\title{
ANALYSIS OF PERFORMANCE OF Q ROUTES FOR ESTABLISHING FUTURE DESIGN CRITERIA
}

\author{
Akshay Belle, Lance Sherry, Ph.D, Center for \\ Air Transportation Systems Research, Fairfax, \\ VA-22030.
}

\author{
Arash Yousefi, Ph.D, Jerome Lard, Ph.D, \\ Metron Aviation Inc, Herndon, VA-20170.
}

\begin{abstract}
$\mathrm{Q}$ routes are en route airway routes, between FL180 and FL450, which can be flown by RNAV equipped aircraft capable of conforming to navigation specified by RNAV 2. Q routes, in use since late 2003, provide more direct routing compared to conventional routes, and are intended to reduce flight distance and travel time.

This paper analyzes the benefits of Q routes by comparing the flight performances along select origin destination (OD) pairs, for first quarter of 2003 and first quarter of 2009. The flight performance is measured by: Distance Flown and Travel Time. The two metrics are computed using flight position updates, for the flight en route phase and for the entire flight leg.

The results indicate that the flight en route performance was statistically improved on Q routes than conventional airway routes in terms of mean Distance Flown (e.g. $+4 \%$ for Q Route 1 ) and mean Travel Time (e.g. $+5 \%$ for Q Route 1 ). The flight leg performance was statistically improved on Q routes than conventional airway routes in terms of mean in Distance Flown (e.g. $+1.2 \%$ for Q Route 3 ) and mean Travel Time (e.g. $+2 \%$ for Q Route 3 ). These results provide useful criteria for future airspace design.
\end{abstract}

\section{Introduction}

The two main components of PerformanceBased Navigation (PBN), as outlined by Federal Aviation Administration (FAA), are Area Navigation (RNAV) and Required Navigation Performance (RNP) [1]. RNAV enables aircraft to fly on any desired flight path within the coverage of ground- or space-based navigation aids, within the limits of the capability of the self-contained systems, or a combination of both capabilities [1]. RNAV aircraft have better access and flexibility for point-to-point and benefit in all phases of flight, including departure, en route, arrival, approach, and transitioning airspace [1].

To capitalize on the advantages of RNAV and improvements in accuracy, integrity, availability, continuity and functionality of flight navigation systems, FAA developed and published fixed RNAV routes. These RNAV routes consist of en route RNAV routes (charted as Q routes) and RNAV Instrument Flight Rules (IFR) terminal transition routes (charted as $\mathrm{T}$ routes).

Q routes are high altitude RNAV routes usable by RNAV-equipped aircraft from flight level (FL) 180 through FL 450. Flights need to be equipped with Distance Measuring Equipment (DME)/DME/IRU or /and Global Positioning System (GPS)/ Global Navigation Satellite Systems (GNSS), to be certified to fly these routes, and should be capable of conforming to navigation performance specified by RNAV 2 [2]. The conformance to RNAV 2 is ensured by Air Traffic Control (ATC) through radar monitoring.

Currently 49 Q routes exist in the contiguous United States (U.S) [3], and more than 95 percent of the U.S. air carrier fleet is capable of using them.

The Q routes were designed to facilitate the en route phase of the flight leg, so as to streamline traffic flowing into high density airspaces and terminal areas. Q-routes provide more direct routing, resulting in shorter flight distance compared to conventional routes [4].

This paper analyzes the benefits of Q routes by comparing the flight performances along select origin destination (OD) pairs, for first quarter of 2003 and first quarter of 2009. The flight performance is measured by: Distance Flown and Travel Time. The two metrics are computed using flight position updates, for the flight en route phase and for the entire flight leg. 
The results indicate that:

- Flight en route performance was statistically improved on $\mathrm{Q}$ routes than conventional airway routes in terms of mean Distance Flown (e.g. $+4 \%$ for $\mathrm{Q}$ Route 1) and mean Travel Time (e.g. $+5 \%$ for Q Route 1 ).

- Flight leg performance was statistically improved on Q routes than conventional airway routes in terms of mean in terms of mean Distance Flown (e.g. $+1.2 \%$ for Q Route 3) and mean Travel Time (e.g. $+2 \%$ for $\mathrm{Q}$ Route 3 ). These results provide useful criteria for future airspace design.

The paper is organized as follows: Section 2 provides the scope of the study, Section 3 describes the methodology applied, Section 4 includes the results, and Section 5 provides conclusions.

\section{Scope of Analysis}

Given the inherent qualities of $\mathrm{Q}$ route design and the fact that flights are in the cruise phase for most part of the Q routes, the following hypothesis is made:

- Q routes have improved flight en route performance, when compared to performance on convectional routes.

Since the en route phase contributed to majority of the flight leg, the second hypothesis follows as:

- Q routes have improved flight-leg performance, i.e., from departure to arrival.

Here the flight performance is gauged in term of the actual distance flown by the flight and time taken to cover the same.

Analysis of traffic flow is done between Seattle-Tacoma International airport (SEA) and four other airports along the west cost of U.S: San Francisco International Airport (SFO), Norman Y. Mineta San Jose International Airport (SJC), Metropolitan Oakland International Airport (OAK) and Los Angeles International Airport (LAX). The $\mathrm{Q}$ routes that connect each of the OD pairs are shown below (see Table 1).
Table 1. OD pairs and $Q$ routes

\begin{tabular}{|c|c|c|}
\hline OD pair & Q route & Length(NM) \\
\hline SEA-SFO & Q1 & 546 \\
\hline SEA-SJC & Q3 & 541 \\
\hline SEA-OAK & Q5 & 523 \\
\hline SEA-LAX & Q7 & 654 \\
\hline
\end{tabular}

The layout of the four $\mathrm{Q}$ route relative to the origin and destination is shown in figure (see Figure 1). Note that though Q1, Q3 and Q5 are parallel and are separated by about 8 miles, they serve just one destination each, as indicated in table (see Table 1).

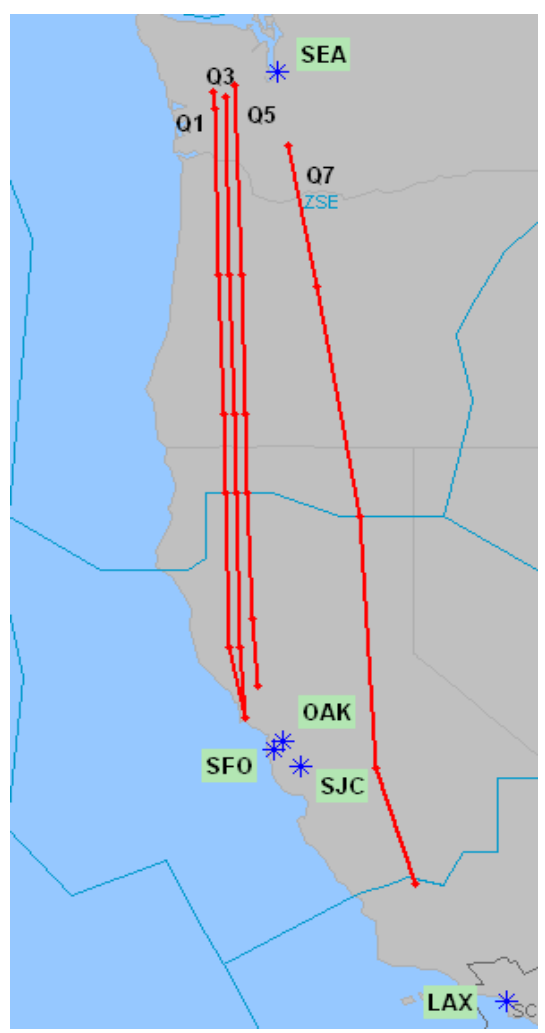

\section{Figure 1. Relative Position of OD pairs and Q routes}

Q routes were published on July 10, 2003 [5], hence it is presumed that until the first half of 2003 flights primarily used conventional routes and navigated directly to and from the beacons. In this analysis, data for the first quarter of 2003 and first quarter of 2009 are considered. The data from the Traffic Flow Management System (TFMS) database maintained by Metron Aviation Inc is used. This data is referred to as flight track data and provides the flight position update with the 
resolution of a minute, i.e. latitude, longitude and altitude for every minute. The flight track data for first quarter of 2003 is used to determine the performance of flights on conventional routes and, the data for first quarter 2009 is used to determine the performance of flights on $\mathrm{Q}$ routes.

To compare the flight performance between the two time periods, metrics Distance Flown and Travel Time are defined as follows:

Distance Flow is defined as the actual distance covered by the flight from origin to destination including any deviations from published route. It is measured in nautical miles (NM). There are many reasons why an aircraft might not be on a published route. Aircraft might be off course due to intervention from an air traffic controller or due to weather [6]. The other possible reason why a flight might deviate from a published route is, that it might not be the most efficient way to get from the origin to destination. Hence looking into the actual distance flown by the flight to reach a particular destination would also provide an insight on the efficiency of route design. It is important that the published routes are efficient in every way possible. To achieve that one needs to have a National Airspace System (NAS) - wide perspective while designing them.

The Travel Time is defined as the time taken to cover the Distance Flown, measured in minutes (min). The time taken by the flight to reach its destination is a function of the Distance Flown and the speed of the aircraft. The speed at which the aircrafts fly depends of the optimal cruise speed, which in turn depends on the aircraft type and altitude. The surge in fuel cost in 2007 has pushed airlines to strike a delicate balance, seeking an aircraft's "sweet spot" on fuel use without slowing down so much that other costs, and flight delays, rise [7]. Hence Travel Time would be any interesting metric to compute and compare for the two time periods.

The computed metric are compared for the two time periods to verify the hypotheses. To what extent the computed metric help in verifying the hypotheses has been discussed. Finally a note on future work and how this analysis helps in providing insight for establishing future airspace design criteria has also been discussed.

\section{Methodology}

The distance between origin and destination is defined as flight leg. The flight leg can be divided into the following phases, liftoff, ascend/climb, en route cruise, descend and touchdown. The actual Distance Flown and the Travel Time for a given flight can be calculated from the flight position update data as shown below (see Figure 2).

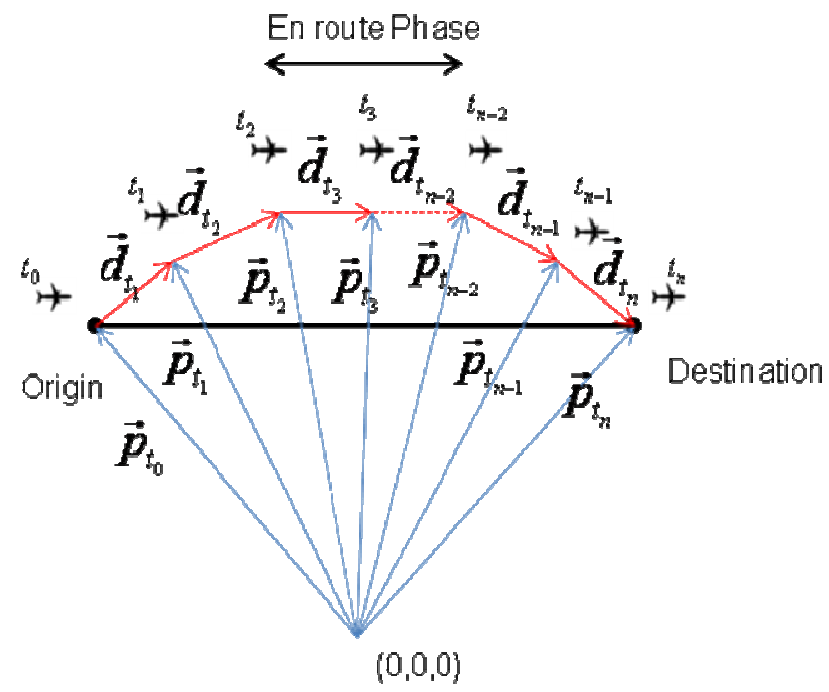

Figure 2. Vector representation of flight leg

The data provides the flight position vector ( $\vec{p}_{t_{i}}$, as indicated by the blue lines) for time steps of one minute. From this the distance vector ( $\vec{d}_{t_{i}}$, as indicated by the red lines) for a given flight is calculated as follows:

$$
\begin{aligned}
& \vec{d}_{t_{i}}=\vec{p}_{t_{i}}-\vec{p}_{t_{i-1}} \\
& \text { Distance Travelled }=\sum_{i=0}^{n}\left\|\vec{d}_{t_{i}}\right\| \\
& \text { Travel Time }=t_{n}-t_{0}
\end{aligned}
$$

Where,

$\vec{d}_{t_{i}}$ - Distance vector of flight for the $t_{i}$ minute.

$\vec{p}_{t_{i}}$ - Position vector of flight at time $t_{i}$.

$t_{i}$ - Time Stamps.

$t_{0}$ - Time at Origin.

$t_{n}$ - Time at Destination. 
The Distance Flown is calculated as the sum of the magnitude of the distance vector as shown above. The Travel time is calculated as the difference between the first and the last time stamp.

To test the first hypothesis the metrics, Distance Flown and Travel Time are calculated for the en route cruise phase. The en route phase is when the flight maintains constant altitude greater than FL180 for considerable amount of time. To gauge flight performance in the en route phase the cruise information i.e., start, end and duration of cruise, needs to be derived from the data based on the altitude information provided for every position update. The start of cruise is identified when the altitude data indicates a constant FL for more than five time steps (in this case 5 minutes), indicating that the flight has reached the cruise altitude. The end of the cruise is identified when the data indicates FL is less than 180 for more than three time steps. The duration of cruise is recorded from the start to cruise to the end of cruise. The en route phase in indicated in the figure (see Figure 2). For the duration of cruise the distance vector for each minute in the cruise phase is computed as before. The sum of the magnitude of these distance vector gives the Distance Flown in the en route phase. The difference between the start time and end time of en route cruise phase is computed to be the Travel Time in cruise phase.

To test the second hypothesis, the metrics are computed for the entire leg, as explained before. The metrics are calculated and compared for first quarter of 2003, when conventional routes were in use and for first quarter of 2009, when Q routes were in use.

\section{Results}

Q routes allow creation of parallel routes where a single route existed before [4]. This in turn increases capacity of airspace. The flight counts for each quarter are tabulated below (see Table 2). The OD pair SEA-SFO showed a $10 \%$ increase in traffic and SEA-LAX showed a $3 \%$ increase in traffic, in the first quarter of 2009 compared to first quarter of 2003. The traffic along SEA-SJC and SEA-OAK for same time frame dropped by $13 \%$ and $3 \%$ respectively. Though there are other factors such as economy and airline network that influence traffic growth between a given OD pair, the availability of efficient RNAV routes could be one of the important factors influencing traffic growth.

Table 2 Flight Count in each quarter

\begin{tabular}{|c|c|c|}
\hline \multirow{2}{*}{ OD Pair } & Route Type & $\begin{array}{c}\text { Flight } \\
\text { Count }\end{array}$ \\
\hline SEA- & Airways(1qtr2003) & 1400 \\
\cline { 2 - 3 } SFO & Q1(1qtr2009) & 1529 \\
\hline SEA- & Airways(1qtr2003) & 839 \\
\cline { 2 - 3 } SJC & Q3(1qtr2009) & 733 \\
\hline SEA- & Airways(1qtr2003) & 1264 \\
\cline { 2 - 3 } OAK & Q5(1qtr2009) & 1238 \\
\hline SEA- & Airways(1qtr2003) & 1507 \\
\cline { 2 - 3 } LAX & Q7(1qtr2009) & 1555 \\
\hline
\end{tabular}

\section{En route Analysis}

\section{Distance Flown}

$\mathrm{Q}$ routes provide more direct routing when compared to conventional routes [4]. Though it is expected that the en route Distance Flown for first quarter of 2009 would be less than that of first quarter of 2003, it is hard to predict by how much. The computed Distance Flown metric for the en route phase are tabulated (see Table 3).

Table 3. En route average Distance Flown

\begin{tabular}{|c|c|c|c|c|}
\hline \multicolumn{5}{|c|}{ Statistics for En route phase } \\
\hline \multirow{2}{*}{$\begin{array}{l}\text { OD } \\
\text { Pair }\end{array}$} & \multirow{2}{*}{ Route Type } & \multicolumn{3}{|c|}{ Distance Flown(NM) } \\
\hline & & Mean & SD & $\begin{array}{l}\text { t- } \\
\text { test }\end{array}$ \\
\hline \multirow{2}{*}{$\begin{array}{l}\text { SEA- } \\
\text { SFO }\end{array}$} & Airways(1qtr2003) & 464.55 & 30.71 & \multirow{2}{*}{$\mathrm{N}$} \\
\hline & Q1(1qtr2009) & 446.54 & 27.96 & \\
\hline \multirow{2}{*}{$\begin{array}{c}\text { SEA- } \\
\text { SJC }\end{array}$} & Airways(1qtr2003) & 481.93 & 27.56 & \multirow{2}{*}{$\mathrm{N}$} \\
\hline & Q3(1qtr2009) & 477.12 & 21.00 & \\
\hline \multirow{2}{*}{$\begin{array}{l}\text { SEA- } \\
\text { OAK }\end{array}$} & Airways(1qtr2003) & 437.05 & 23.10 & \multirow{2}{*}{$\mathrm{N}$} \\
\hline & Q5(1qtr2009) & 432.09 & 20.72 & \\
\hline \multirow{2}{*}{$\begin{array}{l}\text { SEA- } \\
\text { LAX }\end{array}$} & Airways(1qtr2003) & 678.28 & 30.19 & \multirow{2}{*}{ Y } \\
\hline & Q7(1qtr2009) & 675.72 & 27.89 & \\
\hline
\end{tabular}

The average en route Distance Flown between SEA-SFO was $4 \%$ (18NM) less on $Q$ routes compared to convectional for the two time periods. It was noted earlier that the traffic flow between SEA-SFO in first quarter of 2009 was $10 \%$ higher than that of 2003. This indicates that Q routes not 
only make the en route phase more efficient but also increase capacity of airspace. The OD pair SEA-SJC and SEA-OAK showed 1\% (4.8NM) reduction in average en route Distance Flown, for the two time periods. There was no significant change in the average en route Distance Flown for OD pair SEA-LAX for the two time periods, as indicated by the t-test result.

\section{Travel Time}

The computed Travel Time metrics for the en route phase are tabulated below (see Table 4).

Table 4. En route average Travel Time

\begin{tabular}{|c|c|c|c|c|}
\hline \multicolumn{5}{|c}{ Statistics for En route phase } \\
\hline \multirow{2}{*}{ OD Pair } & \multirow{2}{*}{ Route Type } & \multicolumn{2}{|c|}{ Travel Time(min) } \\
\cline { 3 - 4 } & & Mean & SD & $\begin{array}{c}\text { t- } \\
\text { test }\end{array}$ \\
\hline SEA- & Airways(1qtr2003) & 63.77 & 8.04 & \multirow{2}{*}{ N } \\
SFO & Q1(1qtr2009) & 60.93 & 7.99 & \\
\cline { 2 - 4 } SEA- & Airways(1qtr2003) & 66.27 & 7.49 & \multirow{2}{*}{ Y } \\
\cline { 2 - 4 } SJC & Q3(1qtr2009) & 66.54 & 8.08 & \\
\hline SEA- & Airways(1qtr2003) & 59.45 & 7.06 & \multirow{2}{*}{ Y } \\
OAK & Q5(1qtr2009) & 58.97 & 7.09 & \\
\hline SEA- & Airways(1qtr2003) & 89.69 & 8.72 & \multirow{2}{*}{ N } \\
\cline { 2 - 4 } LAX & Q7(1qtr2009) & 91.37 & 10.22 & \\
\hline
\end{tabular}

The average en route Travel Time for $\mathrm{Q}$ routes in comparison to conventional route for each of the OD pairs was as follows. For SEA-SFO there was a $5 \%$ (3 min) reduction in average en route Travel Time, whereas for SEA-LAX the average en route Travel Time went up by .2\% (2 min). For SEA-SJC and SEA-OAK the en route Travel Time was the statistically the same, as indicated by the t-test results.

\section{Cruise FL}

The computed average Cruise FL's for the en route phase are tabulated below (see Table 5). The average en route Cruise FL for $\mathrm{Q}$ routes in comparison to conventional route for each of the OD pairs was as follows. For SEA-SFO there was a 7\% (2300 feet) increase in average Cruise FL, for SEA-SJC there was a 3\% (1000 feet) increase in average Cruise FL, for SEA-OAK there was a $8 \%$ (2600 feet) increase in average Cruise FL and for SEA-LAX there was a 7\% (2300 feet) increase in average Cruise FL. This indicated that $\mathrm{Q}$ routes enable flights to fly higher, making them more fuel efficient.

Table 5. En route average Cruise FL

\begin{tabular}{|c|c|c|c|c|}
\hline \multicolumn{5}{|c|}{ Statistics for En route phase } \\
\hline \multirow{2}{*}{$\begin{array}{c}\text { OD } \\
\text { Pair }\end{array}$} & Route Type & Cruise FL(feet x100) \\
\cline { 3 - 4 } & & Mean & SD & $\begin{array}{c}\text { t- } \\
\text { test }\end{array}$ \\
\hline $\begin{array}{c}\text { SEA- } \\
\text { SFO }\end{array}$ & Airways(1qtr2003) & 334.69 & 35.21 & \multirow{2}{*}{ N } \\
\cline { 2 - 4 } & Q1(1qtr2009) & 357.06 & 39.67 & \\
\hline SEA- & Airways(1qtr2003) & 339.87 & 36.61 & \multirow{2}{*}{ N } \\
SJC & Q3(1qtr2009) & 349.02 & 40.57 & \\
\hline SEA- & Airways(1qtr2003) & 337.43 & 33.37 & \multirow{2}{*}{ N } \\
OAK & Q5(1qtr2009) & 363.74 & 42.74 & \\
\hline SEA- & Airways(1qtr2003) & 339.28 & 35.64 & \multirow{2}{*}{$\mathrm{N}$} \\
LAX & Q7(1qtr2009) & 352.11 & 36.51 & \\
\hline
\end{tabular}

Flight leg Analysis

\section{Distance Flown}

The computed Distance Flown metrics for the entire flight leg are tabulated (see Table 6).

Table 6. Flight leg average Distance Flown

\begin{tabular}{|c|c|c|c|c|}
\hline \multicolumn{5}{|c|}{ Statistics for entire Flight leg } \\
\hline \multirow{2}{*}{$\begin{array}{l}\text { OD } \\
\text { Pair }\end{array}$} & \multirow[b]{2}{*}{ Route Type } & \multicolumn{3}{|c|}{ Distance Flown(NM) } \\
\hline & & Mean & SD & $\begin{array}{l}\mathrm{t}- \\
\text { test }\end{array}$ \\
\hline \multirow{2}{*}{$\begin{array}{l}\text { SEA- } \\
\text { SFO }\end{array}$} & Airways(1qtr2003) & 664.00 & 27.90 & \multirow{2}{*}{$\Gamma$} \\
\hline & Q1(1qtr2009) & 667.92 & 27.32 & \\
\hline \multirow{2}{*}{$\begin{array}{c}\text { SEA- } \\
\text { SJC }\end{array}$} & Airways(1qtr2003) & 680.28 & 18.12 & \multirow{2}{*}{$\mathrm{N}$} \\
\hline & Q3(1qtr2009) & 674.53 & 10.28 & \\
\hline \multirow{2}{*}{$\begin{array}{l}\text { SEA- } \\
\text { OAK }\end{array}$} & Airways(1qtr2003) & 645.26 & 12.43 & \multirow{2}{*}{$\mathrm{N}$} \\
\hline & Q5(1qtr2009) & 637.79 & 11.99 & \\
\hline \multirow{2}{*}{$\begin{array}{l}\text { SEA- } \\
\text { LAX }\end{array}$} & Airways(1qtr2003) & 877.53 & 15.74 & \\
\hline & Q7(1qtr2009) & 877.18 & 14.88 & \\
\hline
\end{tabular}

The average flight leg Distance Flown for Q routes in comparison to conventional route for each of the OD pairs was as follows. For SEA-SFO there was a $.5 \%(3 \mathrm{NM})$ increase in the average flight leg Distance Flown. This was in spite of 4\% (18NM) reduction in average en route Distance Traveled and $5 \%$ (3 min) reduction in average en route Travel Time. The advantage gained in the en route phase seems to have been negated by other factors downstream. The $10 \%$ increase in traffic between 
SEA-SFO in 2009 could have influenced the increase in the average Distance Flow and Travel Time for the flight leg. For SEA-SJC there was a $.8 \%(6 \mathrm{NM})$ reduction in the average flight leg Distance Flown. For SEA-OAK there was a $1.2 \%$ (7NM) reduction in the average flight leg Distance Flown. The average flight leg Distance Flown for SEA-LAX was statistically the same.

\section{Travel Time}

The computed Travel Time metrics for the entire flight leg are tabulated below (see Table 7).

Table 7. Flight leg average Travel Time

\begin{tabular}{|c|c|c|c|c|}
\hline \multicolumn{5}{|c|}{ Statistics for entire Flight leg } \\
\hline \multirow{2}{*}{$\begin{array}{c}\text { OD } \\
\text { Pair }\end{array}$} & Route Type & \multicolumn{2}{|c|}{ Travel Time(min) } \\
\cline { 3 - 4 } & & Mean & SD & $\begin{array}{c}\text { t- } \\
\text { test }\end{array}$ \\
\hline $\begin{array}{c}\text { SEA- } \\
\text { SFO }\end{array}$ & Airways(1qtr2003) & 99.29 & 9.44 & \multirow{2}{*}{ N } \\
\cline { 2 - 4 } & Q1(1qtr2009) & 101.59 & 11.27 & \\
\hline SEA- & Airways(1qtr2003) & 100.51 & 8.13 & \multirow{2}{*}{ N } \\
SJC & Q3(1qtr2009) & 102.63 & 8.23 & \\
\hline SEA- & Airways(1qtr2003) & 96.64 & 7.83 & \multirow{2}{*}{ Y } \\
OAK & Q5(1qtr2009) & 96.88 & 7.28 & \\
\hline SEA- & Airways(1qtr2003) & 124.44 & 8.16 & \multirow{2}{*}{ N } \\
\cline { 2 - 4 } LAX & Q7(1qtr2009) & 129.81 & 9.23 & \\
\hline
\end{tabular}

The average flight leg Travel Time for Q routes in comparison to conventional route for each of the OD pairs was as follows. For SEA-SFO and SEA-SJC there was a $2 \%$ (2 min) increase in the average flight leg Travel Time. For SEA-LAX there was a $4 \%$ (5 $\mathrm{min})$ increase in the average flight leg Travel Time. The average flight leg Travel Time for SEA-OAK was statistically the same. The flights are losing time on the flight leg as whole in spite of gaining time in the en route phase.

\section{Conclusion}

The results indicate that though there is improvement in the flight performance in the en route phase, some of it is lost downstream as the flight completes the leg. This is true especially for SEA-SFO, connected by Q1 (see Figure 3). As the flights approach the Terminal Area, there is wide variation in paths flown that negates gains from the Q- Route.
The flight en route performance on $\mathrm{Q}$ routes was at max 4\%(for Q1) better than conventional routes in terms of mean Distance Flown and 5\% (for Q1) better in terms of mean Travel Time.

The standard deviation about the mean Distance Flown in the en route phase was $10-30 \%$ less for $\mathrm{Q}$ routes. The standard deviation about the mean Travel Time in the en route phase was the same of Q1, Q3, and Q5, and was up by $20 \%$ for Q7.

The flight leg performance on Q routes was at max $1.2 \%$ ( for Q3) better than conventional routes in terms of mean Distance Flown and $2 \%$ ( for Q3) better in terms of mean Travel Time. The standard deviation about the mean Distance Flown for the flight leg performance was $40 \%$ less in case of Q3 and was $2-5 \%$ for the other three routes. The standard deviation about the mean Travel Time for the flight leg was the same for Q3 and Q5, and was up by 1-2\% up for Q1 and Q7.

These results provide the motivation to perform further research to analyze factors downstream of en route phase that influence flight leg performance.

\section{Future Work}

Q routes were developed and published for the purpose of increasing the use of area navigation, and thereby benefit from the reduced mileage, and fuel burn. Though they certainly have improved the en route performance of flight, there are bottle necks in the downstream of the flight leg that negate the benefits of $\mathrm{Q}$ routes. The initial analysis of flight tracks show large deviation from the Q routes as flights approach the destination (see Figure 3). The undesired variance in flight Distance Flown and Travel Time is caused due to these deviations. Some of the factors that lead to such deviations are, bad weather, inefficient integration Q routes with Standard Terminal Arrival Routes (STARs), controller initiated vectoring due capacity constraints at the destination airport, and over scheduling. The steps leading forward would be to investigate the factors that inhibit the potential gain in Distance Flown and Travel Time. This will be achieved by analysis of track data and evaluation of Terminal Area constraints and operations. 


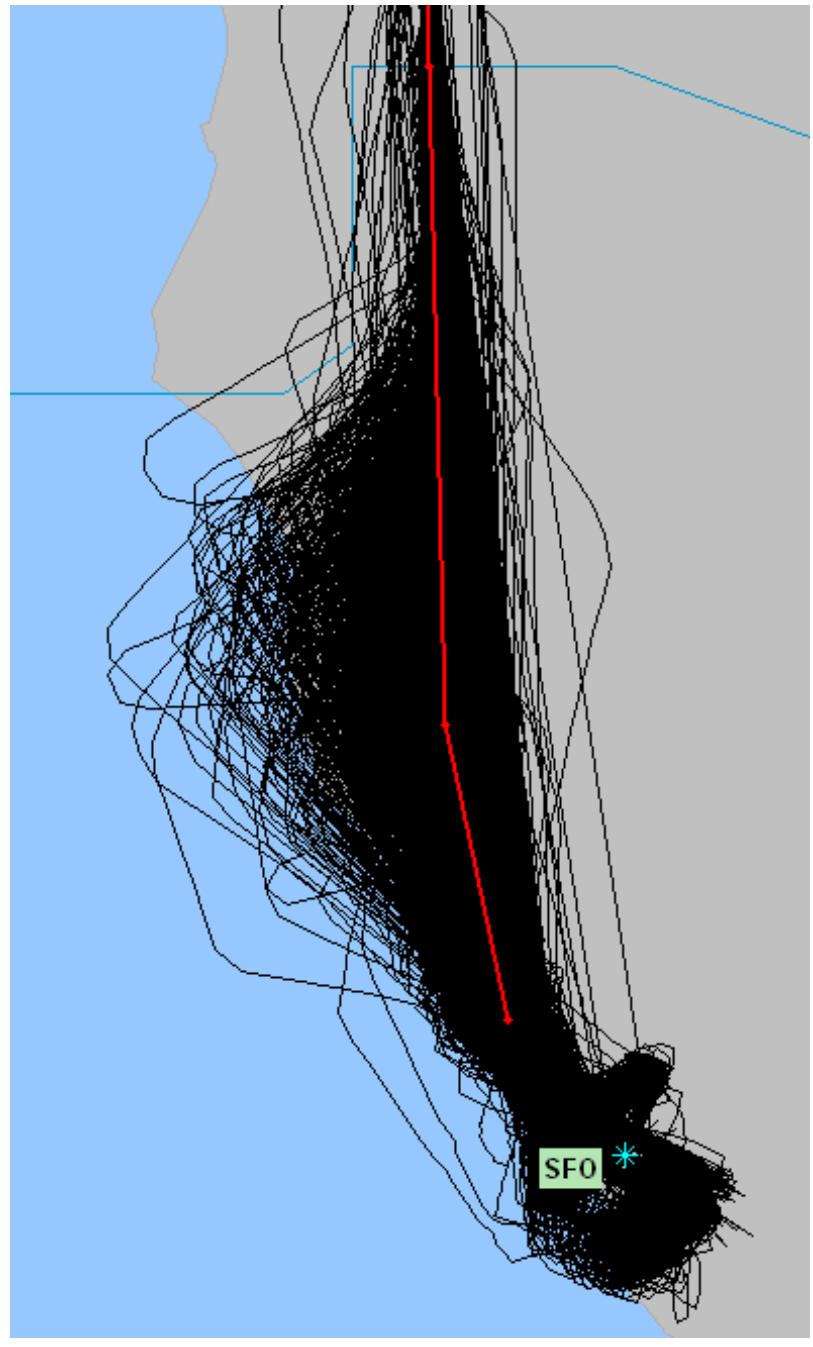

Figure 3. Flight deviations from Q1 close to destination (SFO).

\section{References}

[1] "Fact Sheet," NextGen Goal: PerformanceBased Navigation, RNAV and RNP Evolution Through 2025, Apr. 2009.

[2] "Advisory Circular No: 90-100A, U.S. Terminal and En Route Area Navigation (RNAV) Operations,” Mar. 2007.

[3] "Order JO 7400.9S, Airspace Designations and Reporting Points,” Oct. 2008.

[4] "Q-routes - The Genesis, Evolution, Benefits, and Future of these Highways in the Sky," Air Traffic Bulletin, Sep. 2007, p. 3.

[5] "Advisory Circular No: 90-99, HIGH ALTITUDE AIRSPACE REDESIGN PHASE 1,” Sep. 2003.
[6] J. Krozel, "Intelligent tracking of aircraft in the National Airspace System,” AIAA Guidance, Navigation, and Control Conference and Exhibit, Monterey, CA, 2002.

[7] "Airlines slow down flights to save on fuel Aviation- msnbc.com.”

\section{Integrated Communications Navigation and Surveillance (ICNS) Conference}

May 11-13, 2010 